Results HRMRI provides a detailed benchmark for validation of lumen geometry (Figure 1A, top). Quantitative evaluation of the lumen diameter in the vicinity of the stenosis using imaging data acquired from 7 different centers is presented as weighted mean and standard deviation (Figure 1A, bottom). It was observed that along the centerline of the lumen, the radius ranged from $0.8-1.6 \mathrm{~mm}$ and was highly reproducible across all imaging platforms. The highest CNRs were observed for comparisons between lipid and vessel wall (Figure 1B). CNR mean variation between the two phantom models for each comparison between plaque components was 3.68-6.09, demonstrating excellent reliability in manufacturing technique.

Conclusion A plaque phantom composed of a stenotic vessel wall and plaque components, including fibrous cap and a lipid core, was successfully constructed for multi-center HRMRI standardization.

Disclosures J. Chueh: None. T. Turan: None. K. van der Marel: None. T. LeMatty: None. T. Brown: None. S. Ansari: None. T. Carroll: None. A. Buck: None. X. Zhou: None. A. Chatterjee: None. R. King: None. S. Zheng: None. R. Swartz: None. E. Feldmann: None. M. Gounis: None.

\section{E-017 PURE TENTORIAL SUBDURAL HEMATOMA FROM RUPTURE OF ANEURYSM ALONG THE TRANSMASTOID BRANCHES OF THE OCCIPITAL ARTERY}

H Nguyen, N Doan, S Shabani, M Gelsomino, O Zaidat. Neurosurgery, Medical College of Wisconsin, Milwaukee, WI

\subsection{6/neurintsurg-2016-012589.89}

Background Pure subdural hematoma (without subarachnoid, intraventricular, or intraparenchymal hemorrhage) due to a rupture intracranial aneurysm is a rare pathology. Most reported cases involve an aneurysm along the internal carotid artery, posterior communicating artery, or middle cerebral artery. No reports have documented an aneurysm along the intracranial portion of a branch from the occipital artery.

Case presentation Patient is a 70 year old female, history of hypertension, congestive heart failure, renal artery stenosis, gout, who presented with sudden onset severe excruciating headaches, associated with spinning sensation, nausea, and emesis. No history of trauma. Neurological examination was unremarkable. CT head demonstrated a tentorial subdural hematoma. CTA head revealed a $4 \mathrm{~mm}$ aneurysm along the peripheral left inferior cerebelllum and $3 \mathrm{~mm}$ aneurysm adjacent to the right sigmoid sinus, both without clear visualization of the parent vessels. Diagnostic angiogram revealed

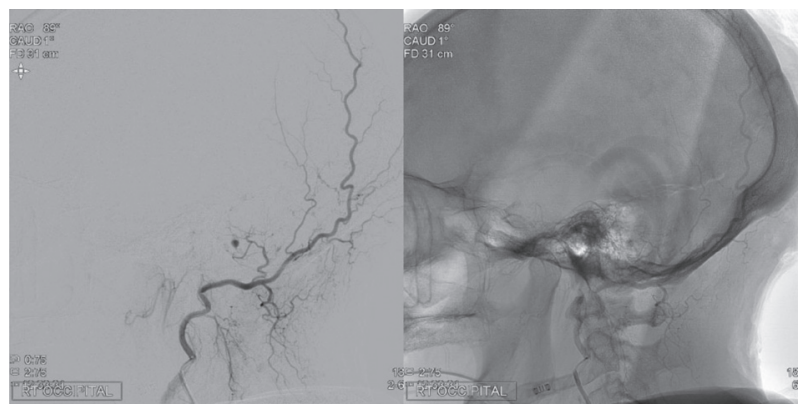

bilateral aneurysms along the transmastoid branches of the intracranial portion of both occipital arteries. Consequently, these branches were embolized, with no residual filling of the aneurysms. Post-procedure, she remained neurologically well. She was monitored appropriately for vasospasm, and discharged home 10 days after presentation.

Conclusion Rupture of aneurysms along intracranial branches of the occipital artery can lead to pure subdural hematoma along the tentorium. For non-traumatic acute subdural hematoma, vigilance should be directed towards a vascular etiology. Disclosures H. Nguyen: None. N. Doan: None. S. Shabani: None. M. Gelsomino: None. O. Zaidat: None.

\section{E-018 TREATMENT OF RUPTURED BLOOD-BLISTER-LIKE ANEURYSMS IN THE SUBACUTE PHASE: CLINICAL AND ANGIOGRAPHIC OUTCOME}

F Di Maria, J Gabrieli, B Bartolini, S Pistocchi, J Chiras, N Sourour, F Clarençon. Neuroradiology, GH Pitié Salpêtrière, Paris, France

\subsection{6/neurintsurg-2016-012589.90}

Purpose Ruptured Blood blisterlike (BBL) aneurysms represent a therapeutic challenge. Timing of treatment and technique of choice are still a subject of debate. We report our experience in the endovascular treatment of such lesions in the subacute phase.

Methods Between June 2011 and January 2015, 6 ruptured BBL aneurysms were treated at our institution. Four were located in the carotid siphon, 2 in the posterior circulation. Endovascular procedures were carried out between day 7 and day 15 after the hemorrhagic event. One patient was treated surgically. Flow-diverter stents (FDS) were used in 4 cases. Two telescopic laser-cut stents were used in one case. Double antiplatelet therapy was started 4 days before treatment in 1 case and the day of the procedure in the remaining 4 cases. Angiographic follow-up was carried out by MRA and DSA at 1 month, 6 months and 1 year.

Results All endovascular procedures were performed without technical difficulties. Antiplatelet treatment was started 4 days prior to procedure in one case and the day of the intervention in the other cases. One patient presented a transient motor deficit at day 1 after treatment. One patient had a peroperative cerebellar ischemia after FDS deployment, despite antiplatelet treatment. One patient treated by surgery had a fatal brain ischemia after peroperative aneurysmal rupture that eventually required clipping of the carotid siphon. Imaging follow was available for the remaining 5 patients. No patent rebled prior to treatment or during follow-up. Three out of five aneurysms were completely occluded at latest follow-up.

Conclusion Modern endovascular techniques for the treatment of ruptures BBL aneurysms, including the use of flow-diversion, seem promising. Treatment in the subacute phase may be considered as an option in relation to other clinical issues (patient WFNS grade, risk of rebleed under antiplatelet therapy, ventricular shunting) when pondering overall risks and benefits in patient management.

Disclosures F. Di Maria: None. J. Gabrieli: None. B. Bartolini: None. S. Pistocchi: None. J. Chiras: None. N. Sourour: None. F. Clarençon: None. 